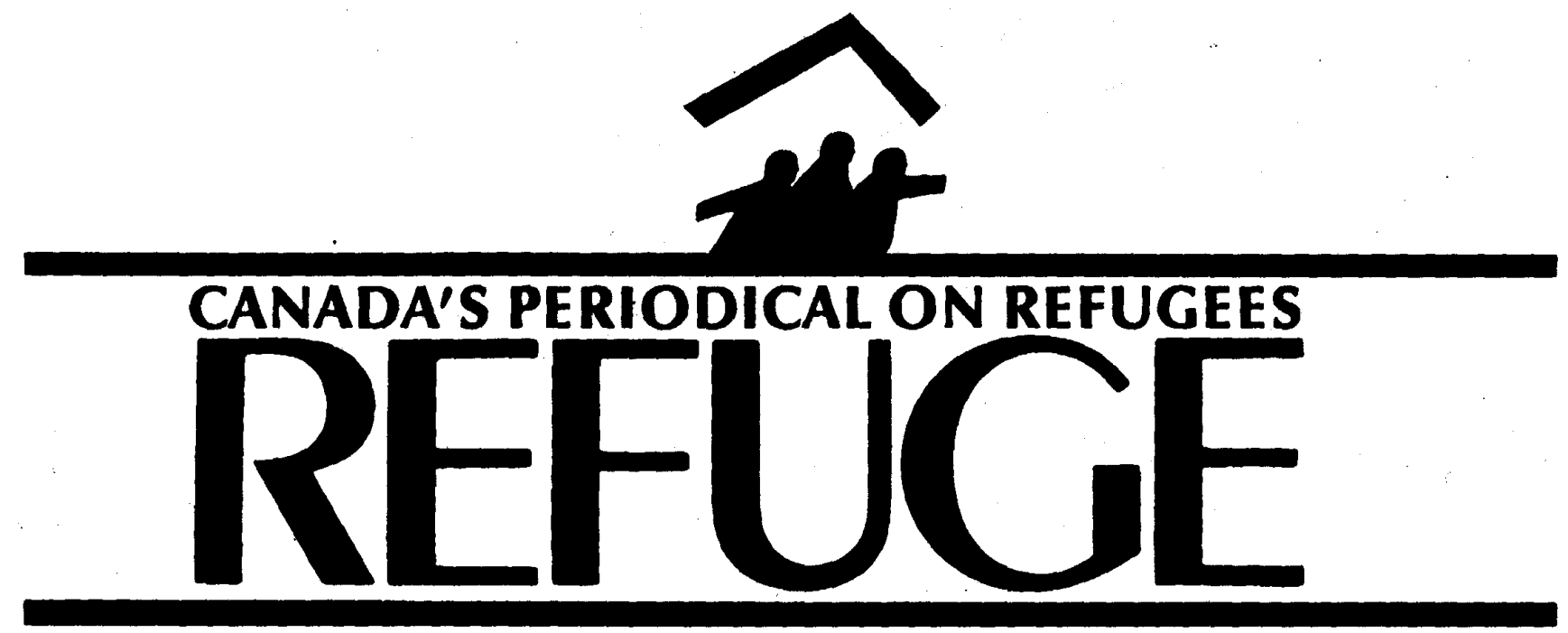

Vol. $14 \cdot$ No. 4

August-September 1994

\title{
Rebuilding Procedures: The Immigration and Refugee Board and Rebuilding Trust
}

There is widespread agreement in this country and abroad that refugee determination procedures should not be adversarial. The conclusion follows from the nature of a request for refuge. There is no adversary to such a request, no opposing testimony to be raised, and no burden of proof to be overcome. There are, moreover, many difficulties of language, communication, and cultural difference. In these circumstances, adversarial procedure is not only unnecessary, but likely to be detrimental. This has been the stated policy of the Government of Canada and the Immigration and Refugee Board (IRB), who have received the benefit of a number of reports, most recently that of Professor James Hathaway, Rebuilding Trust. ${ }^{1}$

However, there now appear to be major conceptual and practical difficulties in implementing this policy, at least in this country. This is evident from a reading of the preliminary response of the IRB to Professor Hathaway's report, in which the Board states that it "has difficulty" considering the changes in procedural responsibili-

\section{H. Patrick Glenn}

ties-directed towards a less adversarial model-suggested by the report, and that it "does not foresee a shift" in the procedural role of Board Members. ${ }^{2}$ How have we managed to reach this point? How has consensus at the level of principle been transformed into apparent discord and reaction at the level of implementation? ${ }^{3}$

In trying to answer these questions it may be useful to turn to some basic principles of procedure. The procedure known and used by North American lawyers, north of the Rio Grande, is usually referred to as the adversarial procedure. It is important to note that it is the procedure which is adversarial, as opposed to the participants in the procedure, or the manner in which it is conducted, or any important element of it, such as cross-examination. Adversarial procedure is usually compared in the Western world with another form of procedure that developed in continental Europe and Latin America, which North American and common law lawyers describe, pejoratively, as "inquisitorial." Here

\section{ConTEnTS:}

Rebuilding Procedures: The IRB and Rebuilding Trust

H. Patrick Glenn

The End of the Cold War, International Disorder, and Refugees:

Laying the Foundations for a "New Wall?" Albrecht Schnabel ...... 4

Accepted on Compassionate Grounds: An Admission Profile of Tamil Immigrants in Canada Arut S. Aruliah.

Early Warning and Conflict Resolution

-An essay review Absalom $M$. Adam

African Refugees: Development Aid and Repatriation

-A book review Charles Smith. 


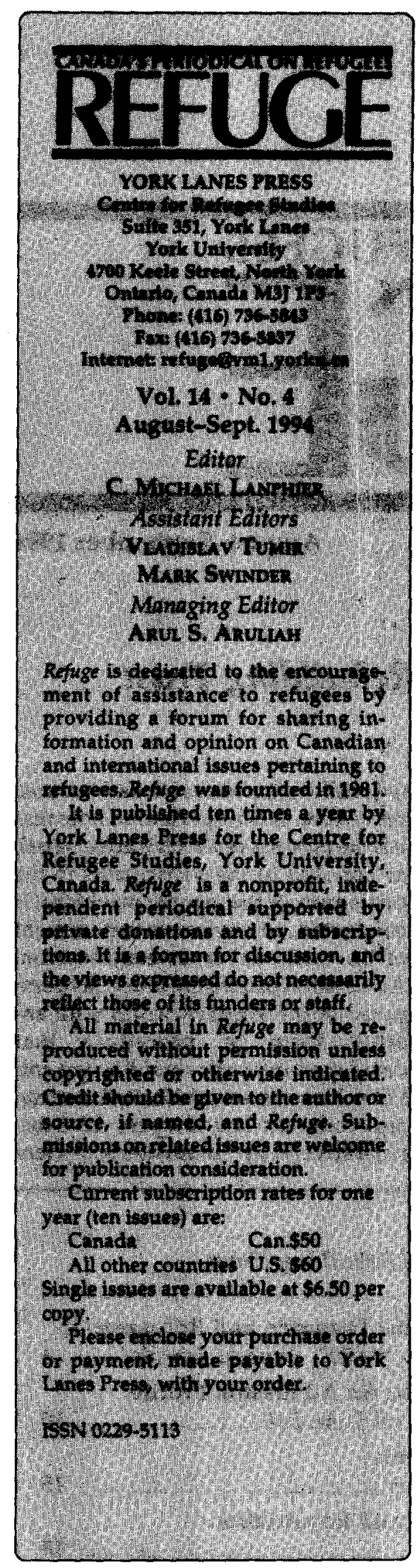

language, tradition, and emotion begin to get in our way. Continental lawyers have a pejorative expression of their own, applied to adversarial procedure, which is "accusatorial." If we try to set aside the pejoratives, however, and simply do what is best for refugees, we should be speaking of two different procedural models, an adversarial and an investigative one. Each presents advantages and disadvantages and each is profoundly rooted in the legal culture from which it is derived. It is the procedure as a whole, however, which is designated as adversarial or investigative, and not any particular element of it.

To reiterate; there is widespread agreement that adversarial procedure is inappropriate for the refugee determination process, for the reasons stated above. This conclusion leaves the investigative model as the main alternative, with whatever modifications are necessary for refugee determination. That model has been widely adopted, most recently by the United States, which implemented an investigative form of procedure for its asylum claims, and rejected the adversarial model used by Immigration Judges in deportation and exclusion proceedings. ${ }^{4}$

The feature which characterizes investigative, as opposed to the adversarial procedure, is the role of the judge or investigator in the control and presentation of the entire case. The procedure is investigative because it is conceived of as an investigation by an investigator. In contrast, adversarial procedure is adversarial because it involves party control and party presentation of a case to a judge or adjudicator. The procedure is that of two presentations, each controlled by a party to the proceedings.

How have these basic procedural concepts been dealt with in the process of establishing refugee determination procedures in Canada? Since 1985, there have been major problems. It does not appear useful to enquire into their causes, which are probably a mix of professional loyalty, tradition, and even downright misunderstanding.
What has occurred, however, is a systematic use of adversarial procedure while the appropriateness of adversarial procedure has been systematically denied. This schizophrenic attitude dates at least from the Plaut report of 1985 .

Rabbi Plaut eloquently defended the case for a procedure in which "all parties shared in the attempt to establish the facts rather than opposed one another. ${ }^{15}$ The adversarial model was, therefore, inappropriate since it presumed "two parties with conflicting financial or other interests," and placed "all the onus of obtaining and presenting information on the parties themselves." 6 . The procedure proposed was thus one of "a cooperative inquiry in which claimant, counsel and the [I]RB member(s) participate." 7 At the same time, however, Rabbi Plaut spoke in terms of, and recommended the major elements of, adversarial procedure. He thus stated a governing principle that "[a]ny person affected by a decision has a right to present his/ her case," and that this right "includes a right to present evidence ...." ${ }^{\prime 8}$ As well, the United Nations High Commissioner for Refugees (UNHCR) and Canada Employment and Immigration Centre (CEIC) could "also provide evidence" 9 and this meant, more precisely, that the CEIC, "when it possesses relevant evidence," may appear at IRB hearings and present it. ${ }^{10}$ Crossexamination was explicitly contemplated although Board members, like judges in adversarial proceedings, could control or limit its scope. ${ }^{11}$

Since 1985, the efforts to square the circle have continued. Even Professor Hathaway's recent vigorous defence of non-adversarial procedure speaks of counsel who "adduce testimony,"12 and Board members who must enforce a prohibition on "non-selective, adversarial cross-examination," while other forms of cross-examination appear contemplated. ${ }^{13}$ In its

H. Patrick Glenn is the Peter M. Laing Professor of Law, Faculty of Law and Institute of Comparative Law, McGill University, Montréal. 
Preliminary Response to Professor Hathaway's report, the IRB continues this process of denial and affirmation. It thus reaffirms its commitment "to the concept of a non-adversarial hearing process for refugee determination"14 while stating, however, that refugee claimants must "know the case they have to meet." ${ }^{15}$. As well, "probing, detailed and assertive examination [by a Refugee Hearing Officer (RHO)] is ... appropriate, if it is necessary to elicit the relevant evidence, even though this may be regarded by some as 'adversarial'." 16 It is acknowledged that "counsel trained in an adversarial mode have not shown much willingness to adapt to an inquisitorial mode."17

The Law Reform Commission of Canada stated accurately and perceptively in 1992 that "... the process before the [Convention Refugee Determination Division] panel is supposed to be non-adversarial. All the details of the adversarial system are present, however, in the examinationin-chief, cross-examination, and re-examination format." 18

Can what is essentially an adversarial procedure, in which parties control and present a case to a judge or adjudicator, be made to function in a non-adversarial manner? The answer to this question is no. An adversarial procedure is, by definition, adversarial. Whether the parties and lawyers involved are polite or impolite, aggressive or non-aggressive, does not change its character. Cross-examination is part of adversarial procedure; it does not become adversarial because it is conducted aggressively. Adversarial procedure, moreover, is not meant to be conducted aggressively or in an overtly hostile manner. Counsel in judicial, adversarial proceedings are meant to be civil. While they are being civil, the procedure they use is adversarial because it is controlled by them and not by the judge or adjudicator. It is, therefore, misleading to state, as the Board does, that "the role of the RHO is not adversarial," while at the same time asserting that "RHO s have a duty to ask the necessary questions to bring out the essential facts of a case." 19 If the RHOs have a duty to ask questions to bring out the facts of the case, their role is adversarial.

There are two major problems in using adversarial procedure while asking the participants not to act adversarially (meaning aggressively), as the Board now does. The first problem is that the procedure remains adversarial, and all of its features which are detrimental to cross-cultural fact-finding, in the non-adversarial context of refugee determination, remain present. This is why the United States rejected adversarial procedure and created a procedure of investigative, collaborative interviewing by Asylum Officers. The second problem is that there is a tendency in adversarial procedure for parties and lawyers to act aggressively. They do so because they are free to do so, and because they may see such conduct as advantageous to the case they are presenting. In civil, adversarial proceedings there is a known and regrettable phenomenon of "Rambo" lawyers. In an adversarial refugee determination procedure, there will therefore be tendencies to aggression and "prosecutorial behaviour." Professor Hathaway found this to be the case with a "significant number" of participants in the Canadian refugee determination process. ${ }^{20}$ We now face, in terms of official, stated policy, the worst of all worlds: The procedure is not what it is meant to be, and it is frequently used in an unjustifiable manner.

It is not clear why this inappropriate, counterproductive situation continues. It cannot be because of simple job protection, since there is as much work to be done in a collaborative, investigative system of procedure as there is in an adversarial one. Nor is it because of a lack of legislative authority, since existing legislation has been found to be sufficiently flexible for investigative procedural techniques to be used. ${ }^{21} \mathrm{~A}$ collaborative, investigative procedure avoids problems of counsel abuse, largely eliminates problems of information gathering and improper "contacts," reduces ex- pensive and intimidating formality, and is compatible with continuing procedural guarantees for refugee claimants and legal aid. It is also best for refugees. Can we not act on the basis of this fundamental agreement?

\section{Notes}

1. James C. Hathaway, "Rebuilding Trust: Report of the Review of Fundamental Justice in Information Gathering and Dissemination at the Immigration and Refugee Board of Canada, 1993."

See also G. Plaut, Refugee Determination in Canada, 1985, and H.P. Glenn, Strangers at the Gate: Refugees, Illegal Entrants and Procedural Justice, 1992.

2. "Preliminary Response of the Immigration and Refugee Board to the Recommendations in Rebuilding Trust, a report by Professor James Hathaway," June, 1994, pp. 10, 18, 19.

3. The Board states, however, that though it has drawn conclusions on some recommendations, it "is open to persuasion that there are other possibilities." Ibid., p. 2.

4. See Tang Thanh Trai Le, "The Legal Status of the Refugee in the United States" (1994), 42 Am.J.Comp.L. 577 at 594, stating that residual use of the adversarial procedure by the Immigration Judge for some asylum applicants reflects a (prejudicial) prejudgment about such applicants, who have either waited until a deportation or exclusion hearing to file for asylum, or who did not receive approval from an Asylum Officer. In contrast, other asylum applicants are entitled to an investigative, non-adversarial procedure.

5. Plaut, supra, note 1 , at p. 122.

6. Ibid.

7. Ibid., p. 123.

8. Ibid., $\mathrm{p} 49$.

9. Ibid., p.123.

10. Ibid., p. 124

11. Ibid., pp. 124,125

12. Hathaway, supra, note 1, p. 74.

13. Ibid., p. 18.

14. Supra, note 1 , at p. 4 . See also the Action Plan announced on release of the Hathaway Report, to the effect that "[ $t$ ] are set up to be and must remain nonadversarial." Press Release, Immigration and Refugee Board, January 25, 1994.

15. Ibid., p. 3.

16. Ibid., p. 9.

17. Ibid.

18. Law Reform Commission of Canada, "The Determination of Refugee Status in Canada: A Review of the Procedure," Draft Final Report, March 5, 1992, pp. 16, 17.

19. Action Plan, supra, note 14, p. 1.

20. Hathaway, supra, note 1, p. 13.

21. Ibid., pp. 11, 12. व 